\title{
Corporate Social Responsibility and Sustainability Challenges for a Bancassurance Company
}

\author{
Emanuele Marsiglia* and Isabella Falautano* ${ }^{*}$ \\ ${ }^{\dagger}$ Pianificazione Strategica, Analisi e Studi, Montepaschi Vita, Gruppo MPS, Via A. Fabrizi 9, Rome 00128, \\ Italy. \\ E-mail: i.falautano@mpv.it
}

This contribution originates from the ideas and discussions during the third edition of the Montepaschi Vita Forum on "The Paradigms of Value. Towards a Good Governance in Financial and Insurance Services: the challenge of ethics, transparency and trust", which took place in Rome, 15 October 2004 and was organized by the MPS insurance pole in partnership with The Geneva Association and Ania. The Forum series are prompted by the awareness of the critical role and nature of the "paradigms of value" topic in the present competitive context of financial services. Value-creation mechanisms are key elements of financial and insurance services, both in the interests of shareholders and, in broader terms, of all stakeholders. The theme of the third Montepaschi Vita Forum was encouraged by the current uncertainty of the financial scenario, in which the rule-based system and the reliability and accountability of several interlocutors is being questioned. The basic assumption is that good corporate governance and corporate social responsibility (CSR) are gradually advancing from a "philanthropic" variant of corporate capitalism to strategic approaches for regaining the trust of clients and society in general. Their role as risk (and also social) managers means that insurers have to work out different models and mechanisms for good corporate governance and CSR in view of a new state of play among the various stakeholders involved. The narrow borderline between legally binding requirements and self-regulatory initiatives has to be borne in mind when addressing topics such as good governance and CSR. A cultural change is involved, transforming a "regulatory compliance" approach into a "regulatory plus" approach. This article focuses on the challenges that MPV, as an insurance company belonging to a banking group with a well-defined CSR strategy, faces in identifying and implementing coherent CSR initiatives and measures.

The Geneva Papers (2005) 30, 485-497. doi:10.1057/palgrave.gpp.2510040

Keywords: insurance; corporate social responsibility; corporate governance; ethics; transparency; regulatory systems; risk management

\section{A framework for ethics in finance: the role of the financial and insurance sectors}

The theme of good governance, ethics, trust and transparency is of increasing relevance in the current financial scenario. Recent crises and corporate scandals

\footnotetext{
* The authors would like to thank the MPV staff, The Geneva Association and Ania for their support in organising the Third Moutepaschi Vita Forum. For information on the Forum Series and the following article: i.falautano@mpv.it; paradigmi@mpv.it
} 
overseas, in Europe and in Italy, have heightened the debate on topics such as corporate governance, the role of financial systems, conflicts of interest, the role and conformation of supervisory authorities and the ethics of economic conduct.

In this context, the so-called "stakeholder approach" is gaining momentum and is more often offered as a viable alternative for going beyond the business vision of "shareholder value", dominant in the last decades and centred on the assumption that the company's sole aim is to produce profit and value for the shareholders. The shareholder vision has been progressively weakened by crises and scandals and it is now generally agreed that the generation of economic value is a necessary but not sole condition for running a business. Other actors have also to be taken into account. Some argue that the adoption of corporate social responsibility (CSR) criteria can represent the most advanced form of the stakeholder approach. ${ }^{1}$ A company, while creating economic value and profit, can espouse social or environmental issues of concern to actors other than the owners.

There is also an increasing consensus that good (corporate) governance goes hand in hand with corporate social responsibility: as the Enron case has taught us, a prizewinning social report is not enough to produce ethical behaviour. In this light the financial system constitutes a kind of crossroads: it is affected by governance problems but at the same time is required to influence the governance of other businesses, the functioning of markets and the ethical conduct of other actors. The governance problems of the financial systems are the subject of debate and legal actions in many countries. The functions of financial systems have been extended and this makes their task of reducing the information asymmetries between savers and payees more complex. Conflicts of interest can pose problems in terms of transparency of relations with the clientele, of redesigning control systems, and in terms of the ways in which savers can protect their interests. ${ }^{2}$

On the other hand, financial institutions could play an active role in inducing other companies to adopt a good governance or to follow corporate social responsibility guidelines. A financial institution that uses its own participation in the business to induce it to respect social sustainability criteria could promote a stakeholder attitude, making the ownership an active party in involving other interests in the corporate management. Naturally, the financial institutions must also base their behaviour on ethical criteria and this comes from the awareness that the yield of financial investments depends on the trend of the real economy. The enduring conviction that it is possible to have capital yields much higher than those of the economic system has favoured speculative attitudes, with the so-called "short-termism" and distortions in corporate management and in market functioning. ${ }^{3}$

It is undoubtedly becoming increasingly important to focus on the corporate social responsibility side. A recent survey marked this trend as a "significant victory in the battle of ideas"; in more skeptical terms CSR could be described as "the tribute that

\footnotetext{
${ }^{1}$ Andriani (2005).

${ }^{2}$ Beltratti (2004).

${ }^{3}$ Andriani, op. cit.
} 
capitalism everywhere pays to virtue". ${ }^{4}$ In this light, it seems indeed undeniable that good corporate governance and corporate social responsibility initiatives involve extra costs in the short-term. However, there are several indicators which point to win-win approaches in the medium-long term for those businesses that are seriously committed. The core issue is how to render compatible the two traditionally opposing terms of "profit" and "good corporate citizenship". And not only for those businesses which have to define a programme of actions to reduce externalized costs (i.e. petroleum companies) or to avoid distributional conflicts. ${ }^{5}$ Good corporate governance and corporate social responsibility initiatives are gradually advancing from a "philanthropic" variant of corporate capitalism to authentic strategies with which to regain the trust of clients and society in general and enhance reputations. Two phrases, only seemingly synonymous, are often used to indicate these new trends: "being held accountable for" and "taking account of". 6 "Accountability" (or better the ability to take responsibility for new concerns) of a firm in general is one of the key elements of its capacity to compete on the global market. And this is even more imperative for financial and insurance businesses.

Their role as risk as well as social managers means that insurers have to work out different models and mechanisms. This is also because of the large number of stakeholders involved in their universe, each with possible conflicts of interest:

- Shareholders, divided into leading shareholders; widespread shareholdings (and minor shareholders, who could upset governance schemes with active engagement); institutional investors (including pension funds, with their "social" role and active ownership strategies).

- Managers, in charge of corporate management and control, with or without stock options and performance-related incentives.

- Employees, understood as human capital and possessing, with shareholders and managers, a "moral constitution", who believe or not in shared values. Tradeunions play an important role in prompting reflection among employees.

- Clients, understood as in-house clients (i.e. in a bancassurance product company, the in-house client is the banking distribution network) and outside clients, linked to the company by contractual, product and/or service networks, including future generations (just think of the role played by insurers in making death risks manageable for families or companies and in natural disaster recovery).

- Suppliers of services/rating companies/auditors, supplying materials/services/forms of control.

- Public institutions linked to the regulatory/supervisory system, guaranteeing the stability of the system, the full competitiveness of the market and transparency (whose role is currently being re-discussed in Italy), and sectorial associations (such as the national insurers association: Ania).

- Local companies/communities in which the insurance company is inserted.

\footnotetext{
4 The Economist (2005).

${ }^{5}$ Heal (2004).

${ }^{6}$ The Economist, op. cit.
} 
The topics are certainly varied and range from the new corporate governance and control schemes to managers' roles, employees' individual ethics, transparency towards clients, competition within a framework of cogent and voluntary regulations, as well as corporate responsibility vis-à-vis society and the community.

Corporate social responsibility implies a variety of mechanisms and formalities. In the specific case of the insurance sector, these can involve:

- In-house corporate mechanisms (organizational, managerial and corporate governance) aimed at introducing an ethical vision, ethical codes and charters of values, extended corporate governance systems, training and upgrading human capital, an Ethical Committee.

- The intermediate stage of communication towards the outside (towards the various stakeholders), flanked by third-parties' certification of the appropriateness of the pathway undertaken; enhancing the corporate reputation (social and environmental reporting, various social and environmental certifications, labeling and transparency strategies).

- The offer of "ethical" products and socially responsible investments (an authentic ethical investing strategy) as well as other corporate social responsibility initiatives (ethical partnerships, foundations).

The context is rendered even more complex by the simultaneous development of regulatory initiatives on several levels, ${ }^{7}$ including:

- Supranational regulatory schemes (i.e. the repercussions of the International Accounting Standards on transparency and of Solvency II for insurers and clients, as well as Basle II for banking groups and the establishment of the single European market for insurance companies).

- National initiatives (i.e. the Sarbanes-Oxley Act in the U.S., the new requirements by the Italian supervisory authority on transparency and disclosure as well as the forthcoming bill of law on Italian regulatory authorities and savings protection).

- Self-regulatory and "voluntary" initiatives in the sector (i.e. the Raising Standards initiative of the Association of British Insurers - ABI, IMSA in the U.S.).

In addition to these three levels of rules, players' strategies have also to be considered as "self-regulatory" and voluntary initiatives, with various supervisory and internal control models set up by financial conglomerates, such as banking groups with integrated bancassurance companies. Strategies for developing human capital and for dialogue with stakeholders (i.e. mutual insurers vis-à-vis the global strategies of internationalized insurance groups).

The regulatory point is crucial. The narrow border line between legally binding requirements and self-regulatory initiatives has to be borne in mind when addressing topics such as good governance and CSR. Thus the mindset of those businesses willing to cope with CSR is not only based on the development of a "compliance" approach towards binding regulations, but increasingly on inserting a "regulatory plus" approach into daily behaviour and corporate practices.

\footnotetext{
${ }^{7}$ Corinti (2005).
} 
As already mentioned, the complexity in this area is also linked to the nature of the insurance sector and its particular social role as a manager of medium-long-term risks following the lifecycle of individuals. By managing mutual risks present in a community, insurance permits individuals to perform activities that they would not always be able to afford on their own; insurance is therefore based on social solidarity and the mutuality of risks within a society. ${ }^{8}$ To quote Atchinson, ${ }^{9}$ the life-insurance industry offers primary social goods, which are its products and which cover needs not just for today but for the long-term future.

The situation is even more complex when insurance companies belong to broader banking groups, especially if the latter have a clearly defined and broad-ranging CSR strategy. In this case, insurance product companies could contribute with their medium-long-term view and their lasting relationship with the clients. It could also be interesting to ask, within the general debate on corporate social responsibility of insurers, a basic question: how to deal with ethics, transparency and social responsibility in the mission of a bancassurance product company?

\section{The particular case of a bancassurance company belonging to a broader banking group}

Before answering the foregoing question, it could be useful to present and analyse briefly the core features of the CSR and "good governance" strategy of Monte dei Paschi di Siena (MPS) Banking Group, in which the Montepaschi Vita (MPV) pole is responsible for its bancassurance activities. MPS Group has particular historical roots and has always been renowned for its protection of the values inherent in the culture of the communities and territories in which it operates. When it was founded in 1472, MPS created and distributed value to the local community (Siena and Tuscany as a whole) for charitable aims, and its banking and credit side gradually started to evolve alongside this activity. Monte dei Paschi was arguably one of the first examples of ethical finance. Now, more than 500 years later, there is a full awareness of the importance and responsibility of the social role played by an integrated banking institution with such a longstanding relationship with the local area. The core issue is how to tackle in a "modern way" present and future challenges in CSR, and several innovative initiatives have been launched to address this matter (i.e. the global "Strategic Plan for CSR" and the "Consumer-Lab" which will briefly be described in the final chapter of this article).

As highlighted by Tonini ${ }^{10}$ and illustrated by the Gruppo MPS social report, ${ }^{11}$ the first formal step towards an authentic socio-environmental awareness dates back to 1998 with the support of the multilateral United Nations Environment Programme (U.N.E.P.). MPS launched a systematic programme of intervention in the socio-environmental sector, based on four main pillars: social responsibility;

\footnotetext{
${ }^{8}$ Foglia (2004).

${ }^{9}$ Atchinson (2004 and 2005).

10 Tonini (2005).

11 Gruppo MPS (2004a, b).
} 
process innovation; product innovation; communication. MPS initiatives in each of the four lines of intervention are outlined here, with their impact on various stakeholders.

In the field of social responsibility, the MPS Board approved in 2000 a "Charter of Values" (Carta dei Valori), a set of principles underpinning the bank's corporate behaviour: ethics of responsibility, customer satisfaction, openness to change, sound business principles and productivity, emphasis on team work and professionalism. This charter had an impact on management systems and external certification and was discussed with all the employees in a series of training courses, to foster cohesion between individual and corporate values. ${ }^{12}$

In the process innovation field there was the definition of an Environmental Management System which obtained the ISO 14001 certification. This system is managed by a specific Unit and an Advisory Board of international experts and the aim is to rationalize all banking activities that could have a social and environmental impact. In 2004 the Advisory Board evolved into a standing Committee on CSR, involving also the MPS top management.

Some of these innovations include the Green Light project for reducing energy consumption and costs of the bank's branches by 15 per cent over 5 years: MPS Bank was awarded the "Green Light Partner" prize by the European Commission in 2003. Moreover, the "green bank" of the Group (Banca Verde) was one of the first banks to receive certification according to Social Accountability 8000 standards.

Some examples of the activities carried out in the product innovation field are those regarding environmental certification and the rationalisation of industrial and energy sources; the enhancement of socially responsible investments under the "Ducato" investment schemes; and the launch of a policy combining an insurance contract and a socially useful project.

In the communications field, the Monte dei Paschi di Siena Bank has been publishing its award-winning Socio-Environmental Report since 2000 and fostering debate to raise public awareness on these issues. ${ }^{13}$

The MPS Group was offered permanent membership in the World Business Council for Sustainable Development in 2002 and its shares have been listed on the Dow Jones Sustainability World Index since September 2002 and the FTSE4Good (Financial Times Stock Exchange four Good) since March 2003. It has recently been announced that MPS, with a few listed Italian companies, has been accepted in the register of ETHIBEL, a Brussels-based consultancy agency for socially responsible investments. ${ }^{14}$ These indexes and ratings are used for the investment choices of ethical funds; a particular feature of these institutional investors is to focus on companies practising high transparency and possessing rigorous in-house control systems. As already recalled, there is a close relationship between "good governance" and "corporate social responsibility".

On a "governance" side, the MPS Bank has the Fondazione Monte dei Paschi di Siena as a major shareholder, a foundation created in 1995 with non-profit

\footnotetext{
12 Gruppo MPS (2004a).

${ }^{13}$ Gruppo MPS (2004b).

${ }^{14}$ Gruppo MPS (2004a).
} 
private legal status. The foundation is linked to the local community and has a broad socially responsible approach. It was the first in Italy to obtain a quality certification for its grant-creating process to enhance its transparency and accountability.

The MPS Bank accepted the Self-Regulatory Code of Listed Companies (Codice Preda) and proceeded to implement its principles in terms of both statutory provisions and working practices. The voluntary adoption of organisational and managerial standards, ensuring the constant respect not only of legal provisions but also of ethical values, is an additional opportunity to improve accountability and relations with public opinion and society as a whole.

This strengthening of the "good governance" programme also meant adapting the group's units for the purpose of defining and implementing socio-environmental policies. Significant examples of this undertaking are the new commercial platforms set up in the sales network. The aim is to improve the ability to personalise services for different clientele needs with a targeted supply and by developing skill-improvement models for human-resource management systems. With regards to the quality of services and products offered, the group's banks have achieved ISO 9001 certification on some of their main products.

The Group also took action on the instructions issued by the Bank of Italy regarding transparency and completed the various stages of the self-regulatory initiative "Patti Chiari" promoted by the national banking association (ABI, see www.pattichiari.it). This entailed considerable effort with regards to organisation, training and ICT facilities. The aim was to grasp the opportunities for improving relations with the clientele by means of a transparent, complete and comprehensible communication.

Concluding these brief considerations on the group's commitment to corporate social responsibility, mention should be made of the results achieved in managing specific problems, such as the complaints regarding financial plans and structured products. The MPS Bank was the first among Italian banks to open conciliatory proceedings with consumer associations. Its effective management of complaints is confirmed by the fact that over 90 per cent of complainants accepted the proposals made during the conciliatory proceedings.

In conclusion, the Bank has been busily engaged in not only complying with regulatory requirements but also going beyond with a "regulatory plus" approach with specific initiatives targeted at the various stakeholders. Although much has been done at a Group level, there is still much to do to implement a "modern" approach to CSR. Worth mentioning here are some recent initiatives, which will require a huge innovative effort in coming years: first, the launch of an integrated CSR Strategic Plan to implement all the socio-environmental guidelines (and specific initiatives for the various categories of stakeholders), as happens for general strategic guidelines within the industrial plan. Second, the so-called "Consumer-Lab", based on an agreement with the major Italian consumer associations (which will be actively involved) and whose main projects for the next years will be linked to the enhancement of transparency and comprehensibility of contracts, the development of common training programmes, the promotion of social banking and the inclusion of needy families and individuals. 


\section{Implementing corporate social responsibility from a bancassurance perspective}

After having introduced the MPS Bank's good governance and CSR strategy, it could be of interest to reflect on the challenges facing the insurance pole within the framework of the more general activities of the broader banking group. Once again, the key question is: how to best introduce ethics, transparency and social responsibility into daily behaviour and into the mission of a bancassurance product company, part of a broader banking group that has developed a particular CSR strategy over its long history, as in the case of the MPS?

Naturally, as an insurance group we are working towards these goals and towards implementing general guidelines and specific initiatives. Nevertheless, if one assumes that insurers are managers of medium-long term risks following the entire lifecycle of clients, there are also other issues involved.

MPV is engaged in both contributing to the CSR strategic framework of the MPS Group and fully complying with all the insurance-specific Italian and European governance and transparency laws. On this second point, the real challenge lies in the ability to go beyond a "compliance approach" towards a "regulatory plus" culture. MPV's approach towards various categories of stakeholder covers three key issues:

- transparency and risk management

- centrality of human resources

- social commitment

representing specific "regulatory plus" commitments (going beyond what is required and prescribed on a regulatory level).

\section{Transparency and risk management}

Transparency has a fundamental and substantial role and not only in terms of support and formal respect of regulations. There are numerous regulatory innovations already introduced or being introduced on the Italian insurance market that concern transparency, ranging from the ISVAP (the Italian supervisory body for private insurance) circulars (just to cite the two most recent ones: n.533 and n. 551) to the adoption (underway) of the directive on insurance intermediation and the Insurers Code, currently being drafted. ${ }^{15}$ Like other operators, we are obviously supporting the activities and proposals of our sectorial association, ANIA, as the banking system has done with the "Patti Chiari" initiative promoted by ABI.

Compliance is fundamental, but what makes the difference is the ability to conceive a "regulatory plus" approach that is either anticipating or offering more than the regulations require in terms of transparency. A recent article spoke precisely of the new competition between insurance companies on transparency and disclosure. ${ }^{16}$ In this light, MPV's policy is not only to make clear what is required by the regulations, but to go beyond and give voluntary information (that is without it being requested) on several items.

\footnotetext{
15 Galli (2005).

16 Sabbatini (2004).
} 
The following are some concrete examples of "regulatory plus" initiatives, all addressed to clients as key stakeholders. Halfway through 2004, the MPV's Board of Directors decided to integrate its annual communication to clients with information on investment lines and on "gestioni separate" (kind of separate funds related to traditional life-policy management in Italy, often accused of being barely understandable in their high technicality), on the asset-mix inside each macro-category and on the most substantial shares inside each fund, all well in advance of binding regulatory requirements. The MPV website also carries information on products in a sort of anticipated compliance with recent regulations.

Another obvious remark is that the quantity of information does not necessarily coincide with "substantial transparency". Sometimes it seems legitimate to ask whether contractual documents, albeit respecting regulatory requisites, are easy to understand for the average person. The challenge is to be formally transparent and at the same time substantially comprehensible. Thus, in 2003 MPV set up a "Product Quality Committee" composed of various managers who, whenever a product or a communication is launched, meet to read, edit and render accessible the information contained in contractual documents. Making transparency a synonym for comprehensibility is not easy: product innovation is time-consuming in that it involves drafting, reading and editing information for the client's use, taking into account increasing product complexity. This activity undoubtedly takes up a great deal of time and resources and there are no immediate returns in terms of increased profits. However, the MPV Group believes in medium- to long-term returns.

The following are some practical examples from customer-satisfaction surveys. In 2001, we realized that MPV clients were less satisfied about the clarity of communication related to their insurance products than about the yields on investments. In 2004, the new survey showed that clients were more satisfied about the former "grey communication areas". Substantial transparency is inseparably linked to comprehensibility and to the dissemination of a better awareness of risk and insurance issues, to prevent diffidence and distrust in a sector with high technicality. To have an informed and aware client in one's portfolio increases the possibility of having a satisfied and loyal client.

Voluntary initiatives by insurers to enhance transparency are fundamental for generating a virtuous circle of information on risks and correct long-term risk management. If the effort is to turn formal transparency into substantial transparency (understood as comprehensibility) in the medium term, then not only insurers but also regulators and consumers (through their trade associations) should play a fundamental role by fostering simplicity in the approach to exhaustive information, with proposals the insurers are willing to discuss and accept. Analyticity and exemplification do not necessary lead to greater simplification.

A further element for reflection is that, even when there is absolute transparency, the intrinsic complexity and technicality of the insurance product still makes it difficult for the average consumer to understand. Thus the trust and ethics factor returns to the fore. For example, drug leaflets can contain all possible information according to the law, but the consultation, professionalism and ethics of the doctor in making a diagnosis and prescribing a treatment remains all important. In the same way, insurers must provide a consultancy service, based on best advice and professional ethics. 
The last reflection on transparency is particularly important in the case of a bancassurance product company that serves a captive distributive network, made up of banks. The first client, the internal client of a product company such as MPV, is the banking network, which has to place the products with its external clients; thus the training and assistance provided to the distributive network during the sales and postsales stage plays a fundamental role.

An additional challenge is related to the delivery of effective training and information, which serves both the network needs (our internal client) and those of the external clients. Final clients' difficulties in comprehending the technicalities of the product are often the same as those encountered by bank colleagues. A huge effort is therefore devoted to training activities addressed to banking employees, who are not specialized in insurance products: the complexity is dealt with upstream, within the product factory. Some figures: in 2004, with over 400,000 clients in the life sector, MPV Client Service dealt with 40,000 telephone calls, sent 1,250 e-mails and the same number of ordinary letters; around 90 complaints arrived, equal to 0.0002 of the number of clients. Although the last figure is more like a dialing code with all its zeroes, MPV is committed to doing even better.

Protecting the client, to whom the numerous transparency, training and information actions are addressed, brings value for the shareholder. The value created must also be preserved over time for the shareholder in order to honour in the long term the commitments made with policy holders, also considering the increasingly important role of insurers as savings managers and institutional investors in Italy. ${ }^{17}$ The insurance sector has to guarantee that money will be still there if and when the risk arises (solvency issue), that it will allow the risk to be covered adequately (profitability issue) and that claims will be paid (governance issue) ${ }^{18}$ The correct management of risks in the medium-long period is part of the particular nature of the insurance business. The insurance group has also invested human and financial resources in implementing risk control systems by setting up a Risk Management Unit.

As a product company, MPV is committed to creating correct products, providing transparent communication and good post-sales management: going further means seeking to guarantee over time the commitment made with regards to both the client and the shareholder.

\section{Centrality of human resources}

Ethical behaviour is first of all an individual issue. And companies are made up of people. The role of individuals, understood as people and as fundamental stakeholders in the company, that is, the employees, is therefore central.

There are two kinds of ethics: individual ethics (from the production line to top management each individual has his or her own personal values and conduct) and corporate ethics, understood as the basic values and corporate identity, thus a kind of "shared ethics".

\footnotetext{
${ }^{17}$ Galli, op. cit.

${ }^{18}$ De Castries (2004).
} 
An important task is therefore to try to make individual and collective behaviour coexistent and coherent. This could be achieved by investing in people and in their training, understood as technical, managerial and also cultural training. In addition to technical and managerial training, each year the insurance group is involved in corporate culture training and brainstorming days involving all MPS group employees. The current edition is addressing precisely the core topics of transparency, ethics and trust. We in fact agree that ethics must come from within an organisation and not be mandated externally. ${ }^{19}$

Another relevant point to be raised in dealing with the stakeholder "employee" is the so-called glass ceiling which, especially in Italy, stops women from holding positions of responsibility. Within the MPV insurance pole this invisible barrier was first tackled in 2002-2004. To give a concrete example, the proportion of female managers out of total executives has risen from 1 to 4 in 2002 to 1 to 2.5 in 2004 . A further step in this direction is the kindergarten project, which will be implemented in the near future.

\section{Social commitment}

A last point concerns social commitment, meaning those initiatives that go beyond philanthropic activities and generous acts, which MPV anyway continues to carry out with the "Montepaschi Vita per 1"Arte' projects (i.e. the restoration of a Hall within the historical building of Palazzo Venezia, the so called "Loggia del Vasari").

In 2004, MPV launched a new life insurance product linked to a socially useful project, named "Sostegno". This policy has Montepaschi Vita and the MPS network committing 50 per cent of commissions to finance the setting up and running of a home for the disadvantaged elderly in Rome. The project, managed by the Sant'Egidio Community, is a demonstration of MPV and MPS's social commitment towards a global problem such as the ageing of the population, with a local dimension (targeted at elderly people in the city in which Montepaschi Vita operates).

\section{Final remarks}

It was stressed at the beginning of this article that the adoption of corporate social responsibility guidelines can represent the most advanced form of a stakeholder approach. However, we are well aware that this has not always occurred, even in the recent history of the Italian system and that it is difficult to achieve coherence since it involves rethinking the way in which value is created, preserved and redistributed.

It is undeniable that corporate social responsibility, ethics and corporate identity have become trendy, often overworked, terms. From a different perspective, the boom of CSR has created a brand new industry, with a flourishing supply of consultancy and auditing services. Nevertheless our Group is convinced that it is possible to go beyond current modes and simple marketing approaches where CSR is considered as "tribute to pay to virtue", without either having a naive concept of doing business or the overconfidence of claiming we are a "good company".

\footnotetext{
19 Atchinson op. cit.
} 
496

Profit remains crucial for the life and health of the business, but one should rise above the bottom line and focus on value creation. To keep a business healthy, it is important to have a solid reputation and an ability to network with various stakeholders, or at very least avoid disservices to the community. In this sense, there is a very fine line between CSR and "good order's sake", but this is the way forward. It is here that corporate citizenship becomes central, in the redistribution of the value created and in the ability to increase it in the medium-long period by protecting and consolidating it, and this is even truer if we consider the social role of insurance. Certainly there are extra costs, albeit rewarding in the medium-long period. Our group is thus also rethinking its way of reconciling ethics and profit.

Montepaschi Vita, and other insurance providers who also belong to banking groups, has to act on several levels. There are activities to develop as active partners of a group like the MPS, which is strongly committed to this issue. The particular features of the sector mean that specific insurance-related activities have also to be developed. And because we are an insurance product company belonging to a banking group we have to add an extra stakeholder to the list - the in-house client represented by the branch colleague.

To sum up, the challenges that the MPV group, as a bancassurance product company belonging to a broader banking group, will be facing are:

- Pro-active participation in the integrated CSR Strategic Plan, becoming involved on a group level in initiatives addressed to various stakeholders and making ad hoc commitments in our capacity as product company and insurers.

- Continuing to create, protect and redistribute value within the MPS group and to policyholders, managing and protecting, in our capacity as insurers, the balance between assets and liabilities in a medium-long-term approach.

- Fostering the general awareness that the insurance sector has a peculiar role as manager of medium-long-term risks throughout the lifecycle of individuals and society. A long-term vision is necessary to go beyond short-termism and to reestablish ethics in business, and insurers have to play an inportant role in fostering this vision.

- The centrality of transparency in an insurance company. It is important to apply a "regulatory plus" approach, going beyond a simple compliance with regulatory requirements on customer protection and transparency. Formal transparency should not be incompatible with substantial transparency and comprehensibility.

Now the challenge will be how to convince skeptics that "doing good by doing well" (to use Heal's words) is not just a catchword and empty promise but a specific assumption of responsibility that goes well beyond simple declarations of principle to deal with facts.

\section{References}

Andriani, S. (2005) 'Introductory address to the Third Montepaschi Vita Forum, The Paradigms of Value. Towards a good governance in financial and insurance services: The challenge of ethics, trust and transparency', Etudes and Dossier n.292, working paper series of The Geneva Association, February 2005. 
Atchinson, B. (2004) 'Ethics, governance, trust, transparency and customer relations', The Geneva Papers on Risk and Insurance Vol. 29(1): 40-44.

Atchinson, B. (2005) 'The U.S. case and the role of professional organisations in boosting trust in financial business', The paradigms of value. Towards a good governance in financial and insurance services: The challenge of ethics, trust and transparency, Etudes and Dossier n.292, working paper series of The Geneva Association, February 2005.

Beltratti, A. (2004) L'impatto globale dell'azienda: la rilevanza della governance e della responsabilità sociale, Background Study for the Third Montepaschi Vita Forum, Rome: 15 October 2004, mimeo.

Corinti, A. (2005) 'Transparency and accontability in the international insurance regulatory framework', The Paradigms of Value. Towards a good governance in financial and insurance services: The challenge of ethics, trust and transparency, Etudes and Dossier n.292, working paper series of The Geneva Association, February 2005.

De Castries, H. (2004) 'Ethics, governance, trust, transparency and customer relations', The Geneva Papers on Risk and Insurance Vol. 29(1): 36-39.

Foglia, L. (2004) 'La tutela degli assicurati e della solidità dell'impresa assicurativa', in A. Scarioni (ed) L'assicurazione e l'etica del business, Milan: Irsa, Giuffrè Editore.

Galli, G. (2005) 'Governance and transparency in the Italian insurance industry', The paradigms of value. Towards a good governance in financial and insurance services: The challenge of ethics, trust and transparency, Etudes and Dossier n.292, working paper series of The Geneva Association, February 2005.

Gruppo, M.P.S. (2004a) La Responsabilità sociale del Gruppo Monte dei Paschi di Siena, Siena, November 2004.

Gruppo, M.P.S. (2004b) Bilancio Socio-Ambientale, Siena, November 2004.

Heal, G. (2004) Corporate Social Responsibility - An Economic and Financial Framework, Background Study for the Third Montepaschi Vita Forum, Rome: 15 October 2004, mimeo.

Sabbatini, R. (2004) 'MPS scatta sulla disclosure', Il Sole 24 Ore, 20 July 2004, p. 29.

The Economist (2005) 'The Good Company. A Survey of Corporate Social Responsibility', 22 January 2005.

Tonini, E. (2005) 'Introductory speech to the third Montepaschi Vita Forum, The Paradigms of Value. Towards a good governance in financial and insurance services: The challenge of ethics, trust and transparency', Etudes and Dossier n.292, working paper series of The Geneva Association, February 2005.

\author{
About the Authors \\ Emanuele Marsiglia is General Manager of Montepaschi Vita. \\ Isabella Falautano is International Relations and Research Manager as well as \\ scientific coordinator of the MPV Forum series.
}

